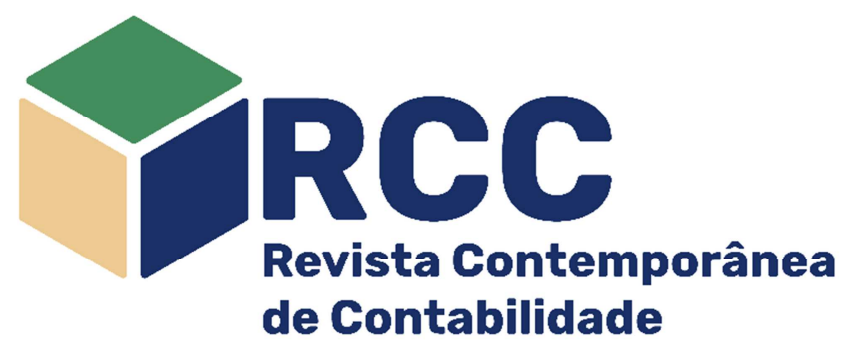

\title{
Divulgação do relato integrado: um experimento sobre o julgamento e tomada de decisão de investidores
}

\author{
Disclosure of the integrated report: an experiment on investor's judgment and decision-making
}

Divulgación del informe integrado: un experimento de sentencia y toma de decisiones del inversor

\author{
Pâmila Eduarda Balsan Colla* \\ Mestre em Contabilidade (UNIOESTE), \\ Pato Branco /PR, Brasil \\ pami_eduarda@hotmail.com \\ https://orcid.org/0000-0003-3252-2500
}

Delci Grapegia Dal Vesco Doutora em Contabilidade e Administração (FURB) Professora do Mestrado em Contabilidade (UNIOESTE), Cascavel/PR, Brasi delcigrape@gmail.com https://orcid.org/0000-0002-0818-3142 (1)

\author{
Simone Boruck Klein \\ Mestre em Contabilidade (UNIOESTE) \\ Mestre em Administração pela Fundação Cultural Dr. Pedro Leopoldo, \\ Cascavel/PR, Brasil \\ simoneboruck@uol.com.br \\ https://orcid.org/0000-0003-4956-7182 (1)
}

\author{
Cleston Alexandre do Santos \\ Doutor em Ciências Contábeis e Administração (FURB) \\ Professor do Programa de Pós-Graduação em Ciências Contábeis \\ (UFMS), Campo Grande/MS, Brasil \\ cleston.alexandre@ufms.br \\ https://orcid.org/0000-0001-7014-6644 (1)
}

Endereço do contato principal para correspondência* Rua Itabira, no 1532, Cento, CEP: 85.5051-286 - Pato Branco /PR, Brasil

\section{Resumo}

Este estudo tem por procedimento um experimento cujo objetivo é verificar se a divulgação do Relato Integrado (RI) por uma organização influencia no julgamento e na tomada de decisão de investidores. Tendo como desenho experimental simples, a variável dependente consiste no julgamento e na tomada de decisão dos participantes, em uma escala de -5 a 5 . A variável independente possui dois níveis, um com a utilização de um conjunto de relatórios contábeis tradicionais, e o outro acrescentando o RI. A amostra foi composta de discentes dos cursos de Ciências Contábeis, Administração e Ciências Econômicas de uma universidade pública do Paraná. A análise ocorreu por estatística descritiva e com o uso do Teste t. Com 269 resultados válidos, inferiu-se que o RI apresenta influência positiva sobre o julgamento e a tomada de decisão de investidores, o que contribui com a literatura por fornecer dados empíricos que corroboram os estudos de Atkins e Maroun (2015) e Cheng et al. (2015) e como contribuição prática fornece evidências de que o Relato Integrado gera valor para os investidores por intermédio das informações de sustentabilidade da organização. Por ser um estudo incipiente no Brasil, denota-se que limitações quanto aos resultados da técnica estatística são visualizadas, o que indicam oportunidades para a continuidade do trabalho e criação de um campo disciplinar em termos de pesquisas envolvendo RI e tomada de decisão.

Palavras-chave: Relatório integrado; Experimento; Julgamento e tomada de decisão

\begin{abstract}
This experimental study aimed at verifying if the disclosure of the Integrated Report (IR) by an organization influences investors' judgment and decision-making. With a simple experimental design, the dependent variable consists of the participants' judgment and decision-making on a scale from -5 to 5 . The independent variable has two levels: one using a set of traditional accounting reports and the other adding the IR. The sample consisted of students from the Accounting Sciences, Administration and Economic Sciences courses at a public university in the state of Paraná. The analysis was performed using descriptive statistics and the t-test. With 269 valid results, it was inferred that the IR exerts a positive influence on investors' judgment and decision-making. This result contributes to the literature by providing empirical data that corroborates the studies by Atkins and Maroun (2015) and Cheng et al. (2015); as a practical contribution, it provides evidence that the Integrated Report generates value for investors through the organization's sustainability information. As it is an incipient study in Brazil, there are limitations regarding statistical techniques, which provide opportunities for continuity of the work and creation of a disciplinary field in terms of research involving IR and decision-making.
\end{abstract}

Keywords: Integrated report; Experiment; Judgment and decision-making 


\section{Resumen}

Este estudio, que tiene como procedimiento un experimento, tuvo como objetivo verificar si la divulgación del Informe Integrado (RI) por parte de una organización influye en el juicio y la toma de decisiones de los inversores. Con un diseño experimental simple, la variable dependiente consiste en el juicio y la toma de decisiones de los participantes, en una escala de -5 a 5 . La variable independiente tiene dos niveles, uno utilizando un conjunto de informes contables tradicionales y el otro sumando el RI. La muestra estuvo compuesta por estudiantes de los cursos de Contabilidad, Administración y Ciencias Económicas de una universidad pública de Paraná. El análisis se realizó mediante estadística descriptiva y mediante la prueba t. Con 269 resultados válidos, se infirió que la RI tiene una influencia positiva en el juicio y la toma de decisiones de los inversionistas. Esto contribuye a la literatura al proporcionar datos empíricos que corroboran los estudios de Atkins y Maroun (2015) y Cheng et al. (2015) y como aporte práctico, brinda evidencia de que el Informes Integrados genera valor para los inversionistas a través de la información de sustentabilidad de la organización. Al tratarse de un estudio incipiente en Brasil, se ven limitaciones en los resultados de la técnica estadística, que indican oportunidades para continuar el trabajo y crear un campo disciplinar en términos de investigación que involucre RI y toma de decisiones.

Palabras-clave: Informe integrado; Experimentos; Juicio y toma de decisiones

\section{Introdução}

Diante do mercado competitivo, as empresas, principalmente de mercado aberto, passaram a ter novas exigências na exposição de suas informações, seja por pressões coercitivas ou por pressões sociais advindas dos diferentes stakeholders (Soares et al., 2020), isso porque os investidores, sejam de mercado de capitais ou investidores diretos, desejam conhecer e compreender o desenvolvimento das organizações nas quais irão investir (Joos, 2019; Garcia et al., 2019). Dessa forma, a partir do final do século XX, foram desenvolvidos relatórios com o intuito de atender às informações almejadas de cunho social, ambiental e financeiras de forma integrada. Entretanto, devido à quantidade de relatórios, as informações podem se tornar extensas e complexas. Doravante, surgiu a necessidade de unificar a divulgação das informações sociais, ambientais e financeiras em um único relatório, denominado de Relato Integrado (RI), podendo tornar as informações menos complexas em termos de apresentação, facilidade de acesso e uso informacional (Dey \& Burns, 2010).

O RI trata-se de instrumento informacional, apoiado em um paradigma voltado ao pensamento integrado da gestão social, ambiental e financeira da organização, o qual "incentiva as empresas a fornecer uma descrição concisa e holística do desempenho da empresa com base em uma abordagem de 'múltiplos capitais' que descreve o processo de criação de valor de uma organização a curto, médio e longo prazo" (Simnett \& Huggins, 2015, p. 30). O objetivo do Relato Integrado consiste em explicar como uma organização gera valor no decorrer do tempo.

Esse valor não é gerado apenas pela organização ou dentro dela, mas influenciado pelo ambiente externo, pois é criado por meio das relações com as partes interessadas (IIRC, 2015). O Relato Integrado (RI) fornece informações quanto aos impactos do ambiente externo nas organizações e aos capitais utilizados por esta, que são: financeiros, manufaturados, intelectuais, humanos, sociais e de relacionamentos e naturais.

Existe uma crescente iniciativa mundial para a orientação dos elementos e informações que compõem o Relato Integrado (Zhou et al., 2017), a qual resultou em um framework do International Integrated Reporting Committee (IIRC) que contou com a participação do Global Reporting Initiative (GRI) para a sua proposição. Com essa iniciativa, busca-se fornecer uma estrutura que orienta o conteúdo geral dos relatórios organizacionais a fim de dar impulso para que as organizações se utilizem ao longo do tempo do Relato Integrado como padrão de relatos corporativos (IIRC, 2015).

No Brasil, diferentemente de países como a África do Sul, é voluntária a divulgação do Relato Integrado, exceto para empresas públicas e de economia mista. Entretanto, por se tratar de um movimento global, empresas brasileiras têm se utilizado dessa ferramenta para a comunicação e a gestão das organizações (Garcia et al., 2019). Cabe ressaltar que a empresa brasileira Natura S. A. foi uma das precursoras em nível mundial na elaboração do Relato Integrado (Eccles et al., 2011) e participou do programa piloto de elaboração do RI juntamente com outras 11 companhias brasileiras (AES Brasil, BNDES, BRF, CCR, CPFL, Fibria, Grupo Mapfre, Itaú-Unibanco, Petrobrás, Votorantim e Via Gutemberg). Seguindo movimentos internacionais, em 2012, a Brasil Bolsa Balcão (B3) criou o programa "Relate ou explique", no qual as empresas declaram se adotam algum relatório de sustentabilidade; caso contrário, devem explicar o motivo da não adoção (Garcia, et al., 2019).

Alguns estudos têm buscado verificar a relação entre o Relato Integrado e a percepção dos usuários externos. Ahmed Haji e Anifowose (2016) apontam que com o passar dos anos, as organizações têm percebido a correlação positiva existente entre a divulgação no Relato Integrado e a criação de valor organizacional percebido. Em outro estudo, como o de Ahmed Haji e Anifowose (2017), houve um aumento significativo na quantidade de divulgações aos usuários externos após a adoção do Relato Integrado em 
empresas africanas.

O estudo de Du Toit (2017) investigou se os relatos integrados das empresas presentes na bolsa de Johanesburgo possuíam legibilidade para os usuários externos. O resultado apontou que os relatos integrados não são legíveis a toda população; enquanto que Briem e Wald (2018) abordaram as dificuldades e influência social e legal na adoção ou não do Relato Integrado, visto que estas sofrem pressões coercitivas dos stakeholders. O estudo de Atkins e Maroun (2015) investigou as reações iniciais dos investidores institucionais da África do Sul quanto aos primeiros relatórios integrados preparados pelas empresas listadas na bolsa de valores de Johanesburgo. O resultado mostra que os Relatos Integrados são vistos como uma melhoria sobre os tradicionais relatórios anuais das empresas, há mais ênfase em medidas não financeiras e evidências de um esforço para integrar métricas financeiras e ambientais, sociais e de governança para fornecer um melhor entendimento da sustentabilidade organizacional.

Cheng et al. (2015) evidenciam que o Relato Integrado trata de aspectos estratégicos das informações, os quais são relevantes para a tomada de decisão nos investimentos. Os estudos de Jones et al. (2007), Hong e Kacperczyk, (2009) e Zhou et al. (2017) abordam a pré-disposição dos investidores em aceitar uma menor taxa de retorno como resultado da redução do risco devido a maiores níveis de divulgações de informações não financeiras e voluntárias, como no caso do Relato Integrado. Nota-se que os estudos referentes ao tema apresentam diferentes abordagens e perspectivas de pesquisa, no entanto, não foram encontrados estudos que investiguem a influência do Relato Integrado no julgamento e tomada de decisão de investidores. Lacuna que ao ser preenchida pode contribuir com particularidades advindas da elaboração e divulgação do RI.

Em face do exposto, a pergunta de pesquisa que norteia este estudo é: a divulgação dos relatos integrados tem influência positiva sobre o julgamento e tomada de decisão de investidores? Por conseguinte, o objetivo desta investigação consiste em verificar se a divulgação do Relato Integrado influencia no julgamento e tomada de decisão de investidores. As evidências para o alcance do objetivo da pesquisa foram coletadas a partir de um desenho experimental simples realizado junto a universitários dos cursos de Ciências Contábeis, Administração e Ciências Econômicas.

O estudo justifica-se ao fornecer evidências sobre os efeitos do RI no julgamento dos indivíduos frente ao julgamento e a tomada de decisão dos investidores, fato relevante à medida que diferentes atores nacionais, como empresas, organizações e pesquisadores têm participado desta discussão. Especificamente no que tange à amostra, a pesquisa fornece contribuições ao identificar que o RI afetou a tomada de decisão dos indivíduos, compostos em sua maioria por jovens, que podem ser considerados a nova geração de investidores, de gestores e geradores de informações para a tomada de decisão organizacional, à medida que estão vinculados a cursos da área de negócios. Este estudo também contribuiu para a ampliação da literatura ao agregar evidências acerca do comportamento de indivíduos diante das informações contidas no RI, possibilitando a compreensão desse mecanismo informacional do mercado de investimento.

\section{Referencial Teórico}

\subsection{Relato Integrado e Orientações}

O Relato Integrado (RI) tem como objetivo melhorar as informações quanto à qualidade de sua natureza e, dessa forma, proporcionar financeiro subsídios informacionais aos provedores de capital para uma alocação mais eficiente dos recursos financeiros. Também se propõe a fomentar uma linguagem coesa e otimizada das informações corporativas explorando os fatores que afetam a capacidade das organizações em gerar valor ao longo do tempo. Outro objetivo é promover a gestão da interdependência dos capitais financeiro, manufaturado, intelectual, humano, social, de relacionamento e natural, além de fornecer um pensamento integrado para a tomada de decisão e de ações que focam na geração de valor no curto, médio e longo prazo (IIRC, 2013; Humphrey et al., 2017).

O princípio do RI está na conectividade de informações e difere-se dos outros relatórios e comunicações ao fornecer em seu escopo "a capacidade que uma organização tem de gerar valor no curto, médio e longo prazo" (IIRC, 2013, p.2). Não se trata de um novo relatório a ser desenvolvido, mas da integração de relatórios financeiros e não financeiros (socioambientais) e de governança com pensamento integrado, de forma clara, concisa, consistente e comparável (Humphrey et al., 2017; Garcia et al., 2019). Em termos decisórios, há evidências (Adams, 2017) de que as características do relato, voltada para criação de valor das organizações, pode estar influenciando o pensamento de líderes corporativos e fortalecendo a sua relevância.

Em termos abrangentes, o RI somente é compulsório nas organizações da bolsa de valores de Joanesburgo. Na África do Sul a divulgação ocorre uma vez ao ano e as organizações que não o fazem necessitam justificar o motivo da abstenção. Tal aspecto torna o país pioneiro na utilização deste relatório (Institute of Directors in Southern Africa - Iodsa, 2009). Contudo, há empresas que realizam a sua apresentação de forma voluntária, vide a dinamarquesa Novozymes e a brasileira Natura (Eccles et al., 2011). 
No Brasil, no final do ano de 2018, por meio do Tribunal de Contas da União, o governo brasileiro editou a Diretriz Normativa (DN) TCU 170 (Brasil, 2018) na qual requer a preparação e apresentação de relatório integrado por todos os órgãos e entidades da administração direta e indireta. Também a Lei das Estatais (Lei $n^{\circ} 13.303$ ) já apresentava uma exigência para que as empresas públicas e de sociedade mista elaborassem um relatório integrado (Brasil, 2016).

Referente à sua origem, o RI surgiu de um esforço formado por uma coalizão global de reguladores, companhias, investidores, acadêmicos, instituições sociais e profissionais contábeis na tentativa de fomentar a divulgação integrada de informações voltadas a criação de valor, sendo que o International $<\mid R>$ Framework foi uma das iniciativas desenvolvidas para que a estrutura do Relato Integrado fosse aplicada globalmente. A proposição deste Framework contou com a participação do Global Reporting Initiative (GRI) e do Accounting for Sustainability (A4S) em agosto de 2010 resultando no desenvolvimento do Framework do comitê do International Integrated Reporting Commiittee (IIRC) (Santana et al., 2019).

O desafio do IIRC ao formular o Framework foi de propor um passo a passo para a implementação do Relato Integrado no âmbito da política pública (Eccles et al., 2011). A Organização das Nações Unidas (ONU), pela meta Objetivos de Desenvolvimento Sustentável (ODS) 12.6.1, tem incentivado as empresas para que forneçam informações integradas sobre sustentabilidade em seu ciclo de relatórios. Além disso, existe um movimento global para que a divulgação dos relatórios de sustentabilidade sociais e ambientais seja integrada pelo Relato Integrado (Garcia, et. al., 2019).

No que concerne ao seu conteúdo, o Framework é constituído da utilização da estrutura do relato, dos conceitos fundamentais que embasam a elaboração do Relato Integrado, dos princípios básicos a serem seguidos e dos elementos de conteúdo que devem constar no Relato Integrado. Os elementos de conteúdo dividem-se em oito etapas, sendo elas: visão geral da organização e seu ambiente externo, governança, modelos de negócios, riscos e oportunidades, estratégia e alocação de recursos, desempenho, perspectiva, base para preparação e apresentação (IIRC, 2015).

A estrutura do RI baseia-se em princípios, que são voltados a "encontrar um equilíbrio adequado entre flexibilidade e imposição que reconheça a grande variedade de circunstâncias individuais de diferentes organizações, e que ao mesmo tempo permita um grau suficiente de comparabilidade entre organizações para atender a importantes necessidades de informação" (IIRC, 2015, p. 7). Outro conceito fundamental é o de geração de valor:

O valor gerado por uma organização ao longo do tempo se manifesta por meio de acréscimos, decréscimos ou transformações de capitais causados por atividades e produtos da organização. Este valor possui dois aspectos inter-relacionados. O valor é gerado para: a própria organização, o que permite retornos financeiros aos provedores de capital financeiro; e outros (ou seja, partes interessadas e a sociedade em geral) (IIRC, 2015, p. 10).

As organizações dependem de diversas formas de capital, e a geração de valor ocorre por intermédio desses capitais. Na estrutura do IIRC, os capitais são classificados em capital financeiro, natural, manufaturado, intelectual, humano e social (de relacionamento). Os capitais são apresentados na estrutura do Relato Integrado para dar sustentação teórica ao conceito da geração de valor e como parâmetro para garantir que as organizações consideraram as diferentes formas de capital (IIRC, 2015). Os elementos de conteúdo do Relato Integrado vinculam-se uns aos outros e não são mutualmente excludentes, não são necessariamente apresentados numa ordem linear, pois se conectam entre si e devem ser apresentados de forma a salientar as conexões entre os elementos de conteúdo (IIRC, 2015). A Figura 1 apresenta os elementos que constituem o Framework.

As organizações podem elaborar seus relatos integrados seguindo algumas indagações que o IIRC (2015) fornece para cada um dos elementos. Os temas inclusos no Relato Integrado são determinados a critério de cada organização. Dessa forma, é possível as empresas apresentarem respostas qualitativas quanto às indagações do mercado além de direcionarem o mercado sobre a geração de valor na qual a organização tem buscado sua sustentabilidade futura. Portanto, o Relato Integrado pode ter influência na tomada de decisão dos investidores devido à abrangência e à profundidade de suas informações presentes e que dão vestígios da situação futura da empresa.

\subsection{Relato Integrado e o Julgamento e Tomada de Decisão de Investidores}

O mercado de capitais, a economia, os investidores e negócios em geral necessitam de informações que os auxiliem a realizar julgamentos quanto à valoração das empresas, garantindo a alocação eficiente de recursos (Zhou et al., 2017). Este se apresenta como o maior desafio das organizações que buscam via mercado de capitais o financiamento de suas atividades e ao mesmo tempo 0 desenvolvimento de vantagem competitiva frente a seus concorrentes.

Para Bonner (2007, p. 2), "o julgamento se refere à formação de uma ideia, crença ou estimativa sobre um objeto, um evento, um estado ou outro tipo de fenômeno". Já a tomada de decisão é afetada pelos desejos, como valores pessoais, e pelas crenças, tais como o conhecimento, dos indivíduos (Hastie, 
2001). O Julgamento e Tomada de Decisão (JTD) também leva em consideração fatores comportamentais, ambientais e de tarefas (Santos \& Cunha, 2021). Sob esse enfoque, estudos do processo de julgamento e tomada de decisão têm sido realizados com diferentes ênfases frente ao poder informacional dos elementos aderentes ao RI (Frost et al.; 2007; Cheng et al., 2015; Atkins \& Maroun, 2015; Mervelskemper \& Streit; Zhou et al., 2017).

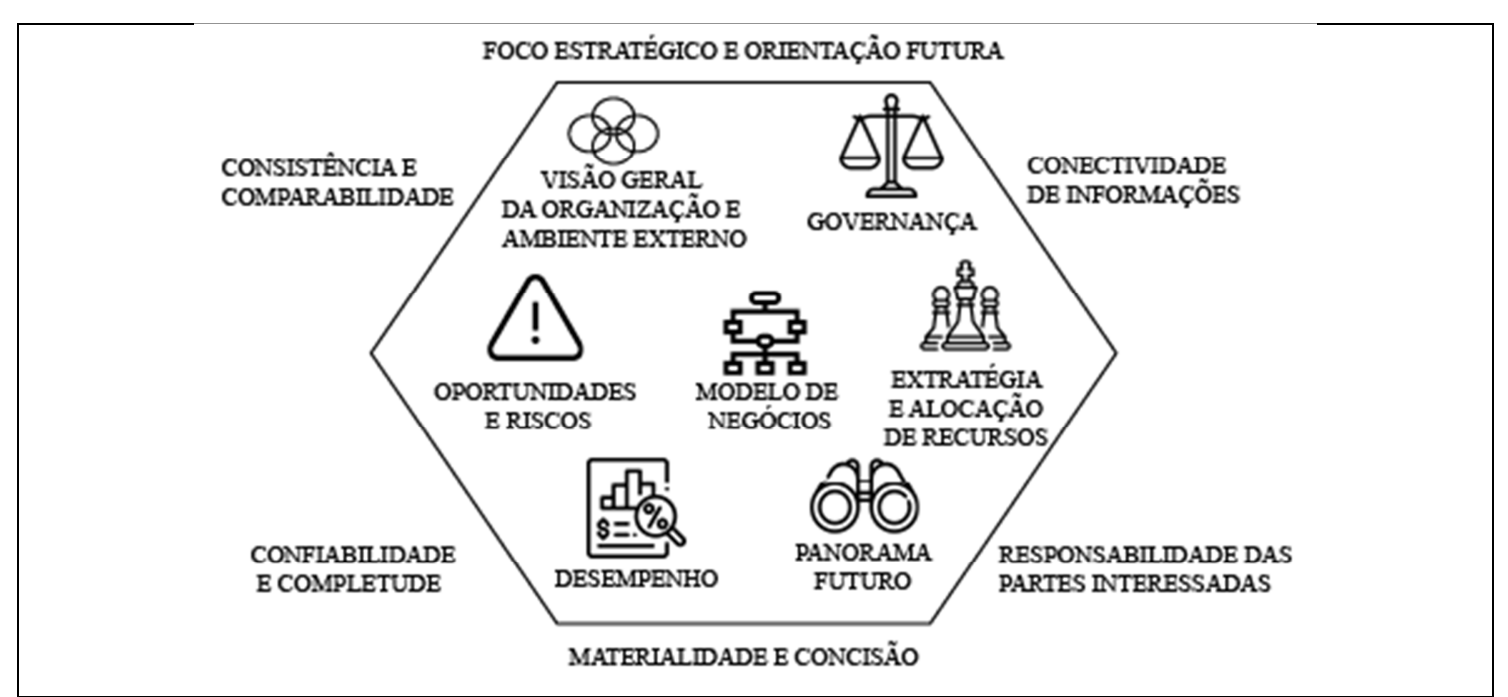

Figura 1 - Elementos de conteúdo do Relato Integrado

Fonte: IIRC (2013).

Frost et al. (2007) reconhecem que o passado histórico dos relatórios econômicos financeiros tem prejudicado o desenvolvimento de comunicações que preguem pela responsabilidade em relação a sociedade e ao meio ambiente. Dessa forma, demandar atenção a esses processos envoltos no escopo ambiental pode resultar em ganhos em termos de regulação e atuação dos acionistas no mercado de capitais. Hong e Kacperczyk (2009) fornecem evidências da influência das normas sociais no mercado de capitais. Para tal, o documento fornece evidências de que as normas sociais podem influenciar significativamente o valor das ações das holdings institucionais.

Cheng et al. (2015) tiveram como foco a análise do efeito da relevância estratégica e da disponibilização de informações de cunho social e ambiental frente às decisões de investimentos profissionais. A pesquisa foi realizada junto a estudantes de pós-graduação do mestrado de Análise Financeira de uma escola internacional de negócios. Os achados mostraram que o Relato Integrado trata de aspectos estratégicos das informações, os quais são relevantes para a tomada de decisão nos investimentos. Particularmente, a pesquisa mostra que as empresas que utilizam indicadores sociais, ambientais e de governança de forma estratégica apresentam uma maior propensão para receber investimentos. Esses achados conduzem a crer que a disponibilização de informações de diferentes esferas, seja social, ambientais e de governança, pode conduzir o comportamento dos indivíduos frente às decisões de investimentos.

Por sua vez, o estudo de Atkins e Maroun (2015) investigou as reações iniciais dos investidores institucionais quanto ao RI preparado pelas empresas listadas na Bolsa de Valores de Johanesburgo. $\mathrm{O}$ resultado mostra que o $\mathrm{Rl}$ é visto como uma melhoria que supre a ausência e a dispersão informacional que estão presentes em relatórios tradicionais anuais e que fornecem um melhor entendimento da sustentabilidade organizacional.

Mervelskemper e Streit (2016) realizaram um estudo que analisou se o Relato Integrado cumpre a sua promessa de melhorar a avaliação do mercado de desempenho sobre os relatórios socioambientais já divulgados. O estudo foi realizado com 217 empresas de 43 países totalizando 852 observações num período de 2010 a 2015, sendo que estas empresas faziam parte do programa piloto da implantação da estrutura do Framework do IIRC. Os resultados mostram que os investidores avaliam os relatórios socioambientais considerando o desempenho das empresas independente da forma escolhida para a divulgação, sendo ela relatório integrado ou socioambiental. As emissões de ambos os relatórios melhoraram a capacidade dos investidores de precificar as ações das empresas. Entretanto, reforça-se a evidência empírica de que a publicação do Relato Integrado pode aperfeiçoar a avaliação dos investidores, sugerindo que este oferece explicações mais eficazes de como a utilização dos diferentes capitais traduz-se em valor de mercado.

O estudo de Zhou et al. (2017) foi realizado com 132 empresas listadas na Bolsa de Valores de Johanesburgo no período de 2009 a 2012, verificando a utilidade das informações contidas no Relato Integrado. Os resultados forneceram evidências de que existe uma diminuição do erro de previsão do analista à medida que aumenta o nível de alinhamento de uma empresa com a estrutura do Framework do 
Relato Integrado, além de estar associado a uma redução subsequente no custo do capital próprio para certas empresas que se utilizam do Relato Integrado. Os resultados obtidos após o controle de fatores relacionados à transparência financeira e à emissão de relatórios não financeiros independentes sugerem que o Relato Integrado está fornecendo informações úteis ao mercado de capitais, além dos mecanismos de relatório existentes. Dessa forma, os resultados encontrados pelos autores sugerem "que as informações contidas em um relatório integrado são úteis para analistas na avaliação do futuro desempenho financeiro das empresas" (Zhou et al., 2017, p. 94).

Os efeitos da disponibilização de informações contidas no RI frente aos comportamentos positivos de julgamento e tomada de decisões por parte dos usuários podem ser explicados a partir de uma perspectiva psicológica. Bucaro et al. (2020) explicam que os indivíduos tendem a perceber as informações de forma unidimensional. Assim, se as informações forem fornecidas de forma separada para um possível investidor, este tende a destinar um maior enfoque para cada dimensão. A partir da perspectiva apresentada pelos autores, acredita-se que se as informações do RI fossem apresentadas juntamente com as demonstrações financeiras tradicionais, os investidores tenderiam a atribuir uma maior importância as informações com enfoque financeiro. Portanto, ao integrar os diferentes capitais em um relato único, mas separado das demonstrações tradicionais, é fomentado no indivíduo um julgamento multidimensional, no qual as diferentes categorias informacionais são visualizadas de forma separada e despertam interesses semelhantes no investidor, no qual um enfoque não acaba sendo priorizado em detrimento do outro.

Haji et al. (2021), ao realizarem um experimento descobriram que as medidas de desempenho de responsabilidade social corporativa têm um impacto nas estimativas de valor da empresa. Dessa forma, acredita-se que a velocidade crescente da necessidade de divulgação fidedigna quanto à responsabilidade junto aos mais plurais capitais disponíveis para a empresa é um movimento que marca os processos decisórios no ambiente de bolsa de valores. Esse cenário pode ser visualizado como uma tendência mundial quanto ao estabelecimento de classificações de sustentabilidade com vistas a prestar contas à sociedade.

Dessa forma, as evidências e discussões apresentadas conduzem a hipótese de pesquisa a qual defende que:

HT: A divulgação dos Relatos Integrados influencia positivamente no julgamento e tomada de decisão de investidores.

Aceitar esta hipótese de pesquisa implica em contribuir com os aspectos teóricos que estão envoltos na temática $\mathrm{Rl}$ e decisão e ainda contribui para criar um ambiente prático no que concerne levantar subsídios para a permeabilidade do RI junto às empresas brasileiras.

\section{Procedimentos Metodológicos}

Um experimento procura criar um ambiente favorável à geração de dados para a pesquisa. A contar da manipulação proposital de variáveis, realizada com a utilização do princípio da aleatoriedade, permite o pesquisador controlar o ambiente de pesquisa e isolar os efeitos das variáveis que seriam confundidas no ambiente natural (Spinkle, 2003). A vantagem do método experimental consiste na sua capacidade de isolar fatores e permitir conclusões acerca do comportamento de certos fenômenos (Libby et al., 2002), gerando maior validade interna do método de pesquisa.

\subsection{Participantes do experimento}

A amostra deste estudo é composta de discentes da graduação de todos os períodos dos cursos de Ciências Contábeis, Administração e Ciências Econômicas de uma instituição de Ensino Superior pública do estado do Paraná, totalizando 271 participantes do experimento. O experimento foi operacionalizado no período do dia 25/11 ao dia 02/12 de 2019, conforme Tabela 1.

\section{Tabela 1}

Datas da Aplicação do Experimento

\begin{tabular}{|c|c|c|}
\hline 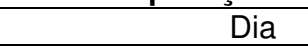 & Curso & Período \\
\hline $25 / 11$ & Ciências Econômicas & $1^{\circ}$ e $2^{\circ}$ \\
\hline $26 / 11$ & Administração & $1^{\circ}$ e $2^{\circ}$ \\
\hline $27 / 11$ & Ciências Contábeis & $1^{\circ}$ e $2^{\circ}$ \\
\hline $28 / 11$ & Ciências Econômicas & $3^{\circ}$ e $4^{o}$ \\
\hline $28 / 11$ & Administração & $3^{\circ}$ e $4^{\circ}$ \\
\hline $02 / 12$ & Ciências Contábeis & $3^{\circ}$ e $4^{\circ}$ \\
\hline
\end{tabular}

Fonte: Elaborada pelos autores (2021).

Após a tabulação dos dados, foram considerados válidos 269 participantes, dois foram excluídos pela incompletude dos dados. A realização da pesquisa com estudantes de graduação é justificada de diferentes formas. Primeiro, o perfil destes participantes representa as múltiplas facetas sociais em termos de classe social, conhecimento prévio e interesse por investimentos, fato que pode ser visualizado como 
uma representação da realidade. Nessa linha, a utilização de estudantes graduandos como proxy de investidores tem sido respaldada na literatura por sua diversidade de personalidade, cognitiva e comportamental e pela vasta utilização em estudos de investidores brasileiros, fato que viabiliza a comparação dos achados (Gomes, 2007; Bortoli et al., 2016). Por fim, observa-se que investigar esse grupo de indivíduos nos seus mais diferentes períodos do ensino superior da área de negócios é popularmente reconhecido em nível internacional e tem ganhado espaço no campo disciplinar contábil brasileiro. Tal fato pode representar um ganho para o preenchimento de gaps na literatura pertinente.

\subsection{Constructo da pesquisa}

A Tabela 2 apresenta as variáveis da pesquisa e as formas de mensuração desses elementos.

Tabela 2

Constructo da Pesquisa

\begin{tabular}{cccc}
\hline $\begin{array}{c}\text { Tipo de } \\
\text { Variável }\end{array}$ & Variável & Métrica & Autores \\
\hline Dependente & $\begin{array}{c}\text { Julgamento e } \\
\text { Tomada de } \\
\text { Decisão } \\
\text { (JTD) }\end{array}$ & $\begin{array}{c}\text { Convicção de investimento - Escala (-5: } \\
\text { definitivamente não investiria nesta } \\
\text { empresa... 5: Definitivamente investiria } \\
\text { nesta empresa) }\end{array}$ & $\begin{array}{c}\text { Bonner (2007); } \\
\text { Hastie (2001); } \\
\text { Santos e Cunha (2021) }\end{array}$ \\
\hline Independente & $\begin{array}{c}\text { Tipo de } \\
\text { Relatório }\end{array}$ & $\begin{array}{c}\text { Conjunto de Relatórios Contábeis } \\
\text { Tradicionais; e }\end{array}$ & $\begin{array}{c}\text { Zhou et al. (2017); } \\
\text { Conjunto de Relatórios Contábeis } \\
\text { tradicionais mais Relato Integrado }\end{array}$ \\
\hline
\end{tabular}

Fonte: Elaborada pelos autores (2020).

A variável dependente foi mensurada por escala de 11 pontos $(-5$ até +5$)$, na qual a de menor ponto apresentava a conviç̧ão de não investir na empresa, e a de maior ponto, a conviç̧ão de investir na empresa. A variável independente apresenta dois conjuntos de relatórios contábeis, um somente com relatórios tradicionais, e o outro, acrescido do Relato Integrado.

\subsection{Design experimental}

A pesquisa foi constituída a partir de um design experimental simples, de apenas uma variável independente, tendo dois níveis de análises: um com a utilização de um Conjunto de Relatórios Contábeis Tradicionais e o outro conjunto de Relatório Contábeis tradicionais mais Relato Integrado (RI). Esse desenho experimental possibilita ao pesquisador o controle dos níveis de informações disponibilizado aos participantes. Com a utilização do instrumento de coleta de dados, permite-se a mensuração do julgamento e tomada de decisão dos participantes envolvidos no experimento.

Em cada unidade de pesquisa, entendida nesta investigação como curso e turma, os participantes foram divididos de forma aleatória de acordo com a localização espacial na sala e equitativamente em cada um dos dois grupos (níveis de análise), conforme roteiro experimental padronizado. Os participantes foram orientados pelos investigadores, em fala padronizada com texto previamente estabelecido, inclusive enfatizando a não permissão de comunicação entre si.

Para o desenvolvimento do experimento, algumas medidas de controles foram observadas para neutralizar possíveis ameaças quanto à veracidade do instrumento de coleta de dados e a amostra, possibilitando a validade interna e externa do experimento. Essas medidas de controle estão evidenciadas na Tabela 3.

Nesta pesquisa, o experimento realizou-se intersujeitos, que tem o propósito de entender as diferenças no comportamento entre diferentes grupos de participantes (Aguiar, 2017), com a aplicação de um case com questões de tomada de decisão, seguindo de questionário pós-experimento.

\subsection{Instrumento de coleta de dados}

Após a análise e controle das ameaças de validação interna e externa, os pesquisadores desenvolveram o instrumento de pesquisa definitivo aplicado no experimento. Os dados deste experimento foram operacionalizados a partir de um caso que foi desenvolvido e fundamentado nas demonstrações contábeis dos anos de 2017 e 2018 de uma empresa brasileira do setor de energia elétrica. Foi utilizado o conjunto tradicional de demonstrações contábeis, que é formado por: balanço patrimonial, demonstração de resultado, demonstração de resultados abrangentes, demonstração de mutação do patrimônio líquido, demonstração do fluxo de caixa e demonstração dos valores adicionados. Contemplou-se, dessa forma, a utilização de dados mais próximos da realidade, uma vez que fez uso de dados reais das informações contábeis evidenciadas no portal de relacionamento com os investidores da empresa. 
Tabela 3

Medidas de Controle para Validade Interna e Externa do Experimento

\begin{tabular}{|c|c|c|c|}
\hline & Ameaça & Características & Medidas de Controle \\
\hline \multirow{9}{*}{ 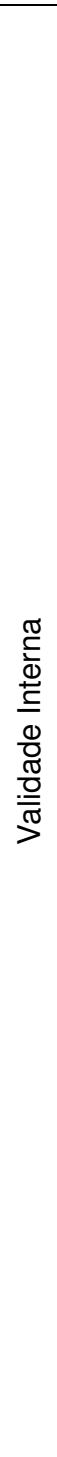 } & Maturação & $\begin{array}{l}\text { Processos vividos pelos sujeitos decorrentes das } \\
\text { passagens do tempo, tais como cansado e fome. }\end{array}$ & $\begin{array}{l}\text { Como procedimento adotado, a } \\
\text { aplicação ocorreu uma única vez } \\
\text { com cada unidade de pesquisa, as } \\
\text { tarefas contemplaram decisões } \\
\text { rápidas e a duração teve no máximo } \\
\text { de } 28 \text { minutos. }\end{array}$ \\
\hline & História & $\begin{array}{c}\text { Acontecimentos específicos que ocorreram entre a } \\
\text { primeira e a segunda medição e que têm efeito } \\
\text { na(s) variável(is) dependente(s)em estudo. }\end{array}$ & Houve apenas uma medição. \\
\hline & Teste & $\begin{array}{l}\text { Refere-se ao que os testes anteriores podem } \\
\text { afetar os resultados dos testes posteriores ao } \\
\text { tratamento experimental. Efeito do pré-teste. }\end{array}$ & $\begin{array}{l}\text { O pré-teste foi realizado com uma } \\
\text { amostra diferente da amostra do } \\
\text { experimento final. }\end{array}$ \\
\hline & Mortalidade & $\begin{array}{c}\text { Perda diferencial dos sujeitos em cada um dos } \\
\text { grupos. }\end{array}$ & $\begin{array}{l}\text { Experimento conduzido uma única } \\
\text { vez com cada grupo, tendo curta } \\
\text { duração. A data agendada para a } \\
\text { aplicação observou o período de } \\
\text { maior presença dos participantes, } \\
\text { evitando datas de avaliações. }\end{array}$ \\
\hline & Instrumentação & $\begin{array}{l}\text { Falta de fiabilidade ou consistência no instrumento } \\
\text { de recolha de dados e respectiva utilização. }\end{array}$ & $\begin{array}{l}\text { As instruções para aplicação do } \\
\text { instrumento foram padronizadas e } \\
\text { fornecidas aos participantes antes } \\
\text { da aplicação do experimento. }\end{array}$ \\
\hline & Seleção & $\begin{array}{c}\text { Resultantes do modo como foram selecionados os } \\
\text { sujeitos. }\end{array}$ & $\begin{array}{l}\text { A composição dos grupos ocorreu } \\
\text { de forma aleatória. }\end{array}$ \\
\hline & $\begin{array}{l}\text { Teste de } \\
\text { Comparação de } \\
\text { Médias }\end{array}$ & $\begin{array}{l}\text { Consequência de terem escolhido sujeitos com } \\
\text { base nos respectivos resultados extremos. }\end{array}$ & $\begin{array}{l}\text { Os participantes foram divididos por } \\
\text { grupos, por aleatoriedade e em } \\
\text { quantidades iguais para fins de } \\
\text { comparabilidade. }\end{array}$ \\
\hline & $\begin{array}{l}\text { Imitação de } \\
\text { Tratamentos }\end{array}$ & $\begin{array}{c}\text { Comunicação entre os participantes pode gerar } \\
\text { ausência de independência de respostas ao } \\
\text { tratamento experimental. }\end{array}$ & $\begin{array}{l}\text { Com aplicação em sala de aula, } \\
\text { uma das instruções passada foi a } \\
\text { não utilização de aparelhos celular e } \\
\text { a proibição de conversar entre os } \\
\text { participantes. }\end{array}$ \\
\hline & $\begin{array}{l}\text { Desmoralização } \\
\text { Ressentida }\end{array}$ & $\begin{array}{l}\text { Diferentes tratamentos experimentais podem } \\
\text { causar diferentes níveis de motivação entre os } \\
\text { indivíduos e impactar nos resultados. }\end{array}$ & $\begin{array}{c}\text { Os diferentes tratamentos } \\
\text { experimentais são fatores inerentes } \\
\text { às informações obtidas e utilizadas } \\
\text { pelos investidores. }\end{array}$ \\
\hline \multirow{3}{*}{$\begin{array}{l}\frac{\pi}{ \pm} \\
\frac{1}{0} \\
\frac{0}{x} \\
0 \\
\frac{0}{0} \\
\frac{\pi}{0} \\
\frac{0}{\pi} \\
>\end{array}$} & $\begin{array}{l}\text { Validade } \\
\text { Populacional }\end{array}$ & $\begin{array}{l}\text { A ausência de Validade Populacional está } \\
\text { relacionada à não representatividade da amostra } \\
\text { em relação à população. }\end{array}$ & $\begin{array}{l}\text { Todo indivíduo pode ser } \\
\text { considerado um investidor, de maior } \\
\text { ou menor grau. A generalização dos } \\
\text { resultados se estendeu para o } \\
\text { contexto da pesquisa. }\end{array}$ \\
\hline & Validade Ecológica & $\begin{array}{l}\text { Refere-se à generalização dos resultados do } \\
\text { estudo para outras configurações experimentais, } \\
\text { contempla a aplicação de experimentos mais } \\
\text { próximos à realidade e uma maior atenção ao } \\
\text { contexto experimental. }\end{array}$ & $\begin{array}{l}\text { O instrumento de coleta de dados } \\
\text { utilizou dados verídicos da } \\
\text { organização, case do estudo, os } \\
\text { quais estão evidenciados no site da } \\
\text { organização. }\end{array}$ \\
\hline & Validade Temporal & $\begin{array}{l}\text { Está associada à generalização dos resultados da } \\
\text { pesquisa ao longo do tempo. }\end{array}$ & $\begin{array}{l}\text { Para a presente pesquisa, a } \\
\text { generalização dos resultados do } \\
\text { experimento está limitada a um } \\
\text { único período temporal. }\end{array}$ \\
\hline
\end{tabular}

Legenda: C. = Ciências.

Fonte: Adaptada de Smith (2003).

Como o objetivo deste experimento consiste em verificar se a divulgação dos relatos integrados influencia no julgamento e na tomada de decisão de investidores, também é utilizado o Relato Integrado da empresa para um dos grupos. No entanto, em virtude do tempo de aplicação do caso, dos custos para aplicação da pesquisa e principalmente pelo desgaste que geraria aos participantes para ler o Relato Integrado da organização, que contém 41 páginas, foi necessária uma adaptação. Utilizou-se uma figura do documento original da empresa que sintetiza as informações de como os capitais geram valor na empresa e uma tabela com os principais indicadores de cada capital com textos explicativos. Buscou-se apresentar dados reais para a pesquisa ao utilizar das próprias informações da empresa. A Figura 2 descreve o case 
aplicado de forma sintetizada e uma síntese das demais informações disponibilizadas aos participantes.

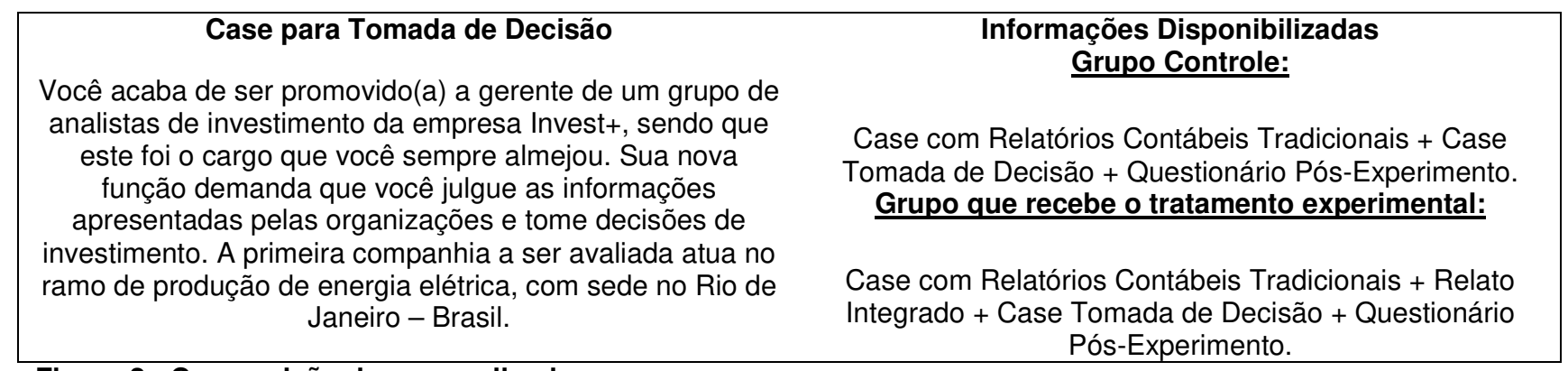

Figura 2 - Composição do case aplicado

Fonte: Elaborada pelos autores (2020).

O instrumento para coleta dos dados conteve duas partes. A primeira foi composta pelo cenário do experimento, enquanto, na segunda parte, o questionário pós-experimento. Na primeira questão, tendo em vista responder à hipótese da pesquisa, o participante do experimento, diante do cenário analisado, decidiu se investiria ou não na empresa (supondo possuir o valor de $\mathrm{R} \$ 100.000,00$ (cem mil reais)), em uma escala entre -5 a +5 . Na sequência, como uma informação complementar para a análise, foi solicitado ao participante mencionar o valor em reais que investiria comprando ações da empresa analisada.

Já o questionário pós-experimento foi composto de questões demográficas para a identificação do perfil dos respondentes e uma questão para identificar quais as demonstrações contábeis com seus respectivos grupos tiveram maior influência sobre o julgamento e a tomada de decisão, assim como uma questão para verificar a influência do Relato Integrado especificamente. Essa última questão utiliza escala entre -5 (Definitivamente sem importância para minha decisão) a +5 (Definitivamente importante para a minha decisão). Vale ressaltar que, para a questão do grupo que não recebeu o Relato Integrado, foi realizada uma adaptação dessa questão.

Foram realizados dois pré-testes, no formato teste piloto, no mês de outubro de 2019. O primeiro com um grupo de 8 pessoas, e o segundo com um grupo de 13 pessoas. Foram realizadas adaptações necessárias ao maior entendimento das questões e dos procedimentos após cada pré-teste realizado.

Para a aplicação do experimento, desenvolveu-se um roteiro de aplicação, que foi seguido visando à uniformização do ambiente a todos os participantes do experimento e controle das ameaças à validade do constructo. Este roteiro possui a explicação detalhada da pesquisa aos participantes, dessa forma objetivouse minimizar vieses na realização da pesquisa. A roteirização também apresenta a forma de preparação dos participantes, que devem ser separados em dois grupos utilizando o princípio da aleatoriedade. Cabe destacar que o fato dos alunos pertencerem a mesma instituição de ensino e terem sido selecionados de forma não probabilística apresenta-se como uma limitação da pesquisa.

\subsection{Procedimentos de análise dos dados}

A análise dos dados ocorreu por métodos estatísticos descritivos e pela aplicação do Teste $t$ e Análise de Variância (ANOVA) com Testes Post-hoc para os dados complementares, entretanto, não apresentaram significância estatística; portanto, não foram utilizadas. No intuito de testar a hipótese teórica de que a divulgação dos Relatos Integrados influencia positivamente no julgamento e tomada de decisão de investidores, foi definido o Teste t. Para o questionário pós-experimento, foi utilizada a análise descritiva.

\section{Resultado 3 Análise dos Resultados}

\subsection{Análise Descritiva das Variáveis}

A variável "julgamento e tomada de decisão para investimentos" foi medida pela escala de -5 até 5 . Na Tabela 4, é apresentada uma síntese da descrição dos dados obtidos de acordo com o sexo e os cursos de graduação que participaram do experimento.

Em análise aos dados apresentados na Tabela 4, percebe-se uma leve predominância dos participantes do sexo masculino, 53\% (143/269) contra 47\% (126/269) do sexo feminino. O curso de Ciências Contábeis foi predominante com 34,57\% (93/269) dos participantes, comparado a 34,94\% (94/269) do curso de Administração e 30,85\% (83/269) do curso de Ciências Econômicas. Alguns dados que se destacam é a dominância masculina na convicção de não investir na empresa ao ser consideradas todas as frequências negativas, enquanto na convicção de investir na empresa não existe diferença relevante entre os gêneros. Outro dado de destaque é a aparente uniformidade entre os gêneros masculino e feminino, nas respostas dos graduandos de Ciências Contábeis, na convicção de investir ou não na empresa. 
Tabela 4

Julgamento e Tomada de Decisão

\begin{tabular}{|c|c|c|c|c|c|c|c|c|c|c|c|c|c|c|c|}
\hline \multirow{2}{*}{\multicolumn{4}{|c|}{$\begin{array}{c}\text { Escala de julgamento e Tomada de } \\
\text { Decisão }\end{array}$}} & \multicolumn{5}{|c|}{ Não Investir na Empresa } & 1 & \multicolumn{5}{|c|}{ Investir na Empresa } & \multirow{2}{*}{ Total } \\
\hline & & & & -5 & -4 & -3 & -2 & -1 & 0 & 1 & 2 & 3 & 4 & 5 & \\
\hline \multirow{2}{*}{\multicolumn{3}{|c|}{ Participantes }} & $\mathrm{N}$ & 7 & 5 & 11 & 7 & 4 & 19 & 27 & 71 & 75 & 34 & 9 & 269 \\
\hline & & & $\%$ & 2,6 & 2 & 4 & 2,6 & 1,4 & 7 & 10 & 26,4 & 27,8 & 12,6 & 3,3 & $100 \%$ \\
\hline \multirow{2}{*}{\multicolumn{3}{|c|}{ Sexo Masculino }} & $\bar{N}$ & 5 & 2 & 7 & 4 & 4 & 10 & 12 & 40 & 36 & 17 & 6 & 143 \\
\hline & & & $\%$ & 3,5 & 1,4 & 4,8 & 2,8 & 2,8 & 14,3 & 8,4 & 2,8 & 2,5 & 11,9 & 4,2 & $100 \%$ \\
\hline \multirow{2}{*}{\multicolumn{3}{|c|}{ Sexo Feminino }} & $\mathrm{N}$ & 2 & 3 & 4 & 3 & 0 & 9 & 15 & 31 & 39 & 17 & 3 & 126 \\
\hline & & & $\%$ & 1,5 & 2,4 & 3,1 & 2,4 & 0 & 7,1 & 11,9 & 24,6 & 30,9 & 13,5 & 2,4 & $100 \%$ \\
\hline \multirow{12}{*}{ 怘 } & \multirow{4}{*}{ ADM } & \multirow{2}{*}{$\mathrm{H}$} & $\mathrm{N}$ & 2 & 0 & 2 & 1 & 1 & 4 & 2 & 15 & 13 & 8 & 3 & 51 \\
\hline & & & $\%$ & 3,4 & 0 & 3,4 & 1,9 & 1,9 & 7,8 & 3,4 & 2,9 & 2,5 & 1,5 & 5,9 & $100 \%$ \\
\hline & & \multirow{2}{*}{$\mathrm{M}$} & $\mathrm{N}$ & 2 & 2 & 2 & 1 & 0 & 3 & 8 & 10 & 8 & 6 & 1 & 43 \\
\hline & & & $\%$ & 4,6 & 4,6 & 4,6 & 2,3 & 0 & 7 & 18,6 & 23,25 & 18,6 & 13,9 & 2,3 & $100 \%$ \\
\hline & \multirow{4}{*}{$\mathrm{CCON}$} & \multirow{2}{*}{$\mathrm{H}$} & $\mathrm{N}$ & 0 & 1 & 1 & 1 & 2 & 2 & 5 & 14 & 11 & 6 & 2 & 44 \\
\hline & & & $\%$ & 0 & 2,3 & 2,3 & 2,3 & 4,6 & 4,6 & 11,4 & 31,8 & 25 & 13,6 & 4,6 & $100 \%$ \\
\hline & & \multirow{2}{*}{$M$} & $\mathrm{~N}$ & 0 & 1 & 1 & 1 & 0 & 4 & 5 & 14 & 11 & 10 & 2 & 49 \\
\hline & & & $\%$ & 0 & 2 & 2 & 2 & 0 & 8,2 & 10,2 & 28,6 & 22,4 & 20,4 & 4,1 & $100 \%$ \\
\hline & \multirow{4}{*}{ ECON } & \multirow{2}{*}{$\mathrm{H}$} & $N$ & 2 & 1 & 4 & 2 & 1 & 4 & 5 & 11 & 12 & 4 & 2 & 48 \\
\hline & & & $\%$ & 4,2 & 2 & 8,3 & 4,2 & 2 & 8,3 & 10,4 & 22,9 & 25 & 8,3 & 4,2 & $100 \%$ \\
\hline & & \multirow{2}{*}{$\mathrm{M}$} & $\mathrm{N}$ & 1 & 0 & 1 & 1 & 0 & 2 & 2 & 7 & 20 & 1 & 0 & 35 \\
\hline & & & $\%$ & 2,8 & 0 & 2,8 & 2,8 & 0 & 5,7 & 5,7 & 20 & 57 & 2,8 & 0 & $100 \%$ \\
\hline
\end{tabular}

Legenda: I =. Incerto; ADM = Administração; CCON = Ciências Contábeis; ECON = Economia; H = Homem; $M=$ Mulher. Fonte: Dados da pesquisa (2020).

Quanto ao tempo de realização do experimento, 61,33\% (165/269) responderam em menos de 10 minutos; destes, 42,42\% (70/165) eram do curso de Ciências Contábeis. Entre os que demoraram de 11 a 20 minutos, que representam 34,57\% (93/269) dos participantes totais, houve um predomínio do curso de Administração 41/93 ou (44\%), os 4,10\% (11/269) que demoraram mais do que 20 minutos, todos (100\%) pertenciam ao curso de Administração. Estes dados podem apontar que indivíduos que se utilizam de demonstrativos contábeis com mais frequência podem vir a tomar decisões mais rápidas.

A Tabela 5 apresenta a variável "julgamento e tomada de decisão" com os dois grupos do experimento, grupo 1 que apresentava somente os relatórios financeiros tradicionais (grupo de controle do experimento) e grupo 2, com os relatórios financeiros tradicionais mais o Relato Integrado da empresa em análise.

Tabela 5

Estatística Descritiva do Constructo Teórico

\begin{tabular}{|c|c|c|c|c|c|c|c|c|}
\hline \multicolumn{3}{|c|}{ Variáveis / Condição } & Mín. & Máx. & Média & Med. & Desvio Padrão & Curtose \\
\hline \multirow{3}{*}{$\begin{array}{c}\text { Fatores } \\
\text { Julgamento } \\
\text { e Tomada de } \\
\text { Decisão }\end{array}$} & \multirow{2}{*}{$\begin{array}{l}\stackrel{0}{0}: \frac{0}{0} \\
\circ \frac{0}{\pi} \\
\stackrel{\circ}{\frac{\pi}{0}}\end{array}$} & Relatório Tradicional & -5 & 5 & 1.49 & 2 & 2,45 & 1,54 \\
\hline & & Relato Integrado & -5 & 5 & 2,02 & 2 & 1,91 & 2,56 \\
\hline & Julgam & Tomada de Decisão & -5 & 5 & 1,74 & 2 & 2,22 & 0,15 \\
\hline
\end{tabular}

Legenda: Mín = Mínimo; Máx = Máximo; Med = Mediana

Fonte: Dados da pesquisa (2020).

De acordo com a Tabela 5, na análise descritiva, os resultados da curtose mostram uma diferença de um ponto a mais para o grupo que detinha o Relato Integrado. Quanto ao teste de média, os achados revelam também um valor maior para o segundo grupo, o que se pode argumentar que o segundo grupo apresenta maior propensão a investir na empresa comparado ao primeiro grupo, este achado condiz com o esperado para este estudo e também corrobora com o estudo de Cheng et al. (2015), ao afirmar que o Relato Integrado representa uma informação de cunho estratégico da organização e, desta forma, relevante para a tomada de decisão dos investidores. O estudo de Atkins e Maroun (2015) também pesquisou as reações de investidores institucionais quanto aos Relatos Integrados e verificou que as empresas pesquisadas o viam como melhoria para o entendimento da sustentabilidade da empresa.

Ademais, o uso da escala de investimento foi averiguado também com os participantes do experimento o valor real que cada participante investiria na empresa. Os resultados mostram similaridade na assimetria próxima de zero e curtose que fornece valores negativos. As distinções entre os grupos de controle e o grupo experimental ocorrem na média do valor real investido, a qual apresenta o valor de $\mathrm{R} \$$ 
29.237,33 para o grupo 1, grupo com relatórios financeiros tradicionais, enquanto o grupo 2, que contém os relatórios financeiros tradicionais mais o Relato Integrado, fornece um investimento de $R \$ 35.845,22$. A mediana para o grupo 1 é de $R \$ 20.000,00$ e para o grupo 2 é de $R \$ 30.000,00$. A moda do grupo 1 é de $R \$$ $10.000,00$ e para o grupo 2 é de $R \$ 50.000,00$. O desvio padrão apresenta menor dispersão no grupo 2 com valor de 24.909, enquanto no grupo 1 fornece o valor de 26.517. Esses achados confirmam que o grupo que detinha o Relato Integrado investiu valor maior nas empresas. O estudo de Zhou et al. (2017) apontou que a utilidade das informações contidas no Relato Integrado diminui o erro de previsão de analistas financeiros além da diminuição do custo do capital próprio, o que pode como parcimônia contribuir para explicar os níveis de investimento realizados pelo grupo com informações advindas do RI.

\subsection{Análise do Resultado do Experimento}

O "Julgamento e Tomada de Decisão" em investimentos foi investigado a partir do pressuposto de que todo indivíduo pode apresentar condições de investir. Não se buscou analisar o perfil individual do investidor, mas verificar o julgamento e tomada de decisão de investidores quanto à utilização do Relato Integrado como informação que pode aferir à organização na geração de valor em curto, médio ou longo prazo. Dessa forma, a influência da utilização do Relato Integrado é investigada neste experimento.

Para verificar se existe diferença estatística entre os resultados dos grupos de cada tratamento experimental, foi realizado o Teste t. Quanto à verificação da normalidade da variável dependente, utilizouse o teste Kolmogorov-Smirnov, no qual o $p$-value (Sig.) apresentou números inferiores a 0,05, isto, a princípio, aponta a não normalidade dos dados por este teste. Entretanto, Hair Jr et al. (2009) afirmam que valores que se enquadram entre -1 e +1 apresentam assimetria nos dados. A "assimetria é a propriedade que indica a tendência de maior concentração de dados em relação ao ponto central" (Corrar Filho et al., 2007 , p. 47). Como a assimetria se encontra dentro deste intervalo, considera-se que os dados em análise são passíveis de serem tratados a partir do Teste t. Vale ressaltar também que, de acordo com Pestana e Gageiro (2003), mesmo que distribuições da dimensão não tenham aderido à normalidade, o uso de testes paramétricos é adequado quando o "n" das amostras em questão seja maior que 30.

A Tabela 6 apresenta a análise do Teste t entre os grupos 1, sem o Relato Integrado, e o grupo 2, que contém o Relato Integrado junto com os demais demonstrativos contábeis da empresa para o julgamento e tomada de decisão de investimento.

\section{Tabela 6}

Análise do Test $t$ de amostras independentes entre os grupos no JTD

\begin{tabular}{|c|c|c|c|c|c|c|c|}
\hline \multicolumn{8}{|c|}{$\begin{array}{c}\text { Painel } \\
\text { Tipo de Relatório }\end{array}$} \\
\hline \multirow{2}{*}{$\begin{array}{l}\text { Julgamento e Tomada } \\
\text { de Decisão (JTD) }\end{array}$} & \multicolumn{2}{|c|}{$\begin{array}{l}\text { Teste de Levene para } \\
\text { igualdade de variâncias }\end{array}$} & \multicolumn{3}{|c|}{$\begin{array}{l}\text { Teste t para lgualdade de } \\
\text { Médias }\end{array}$} & \multicolumn{2}{|c|}{$\begin{array}{c}\text { Média - } \\
\text { Tipo de Relatório }\end{array}$} \\
\hline & $\mathrm{F}$ & Sig. & $t$ & $\mathrm{df}$ & Sig. & Tradicional & Integrado \\
\hline $\begin{array}{l}\text { Variâncias iguais } \\
\text { assumidas }\end{array}$ & 8,72 & 0,003 & $-1,944$ & 268 & ,052 & \multirow[b]{2}{*}{1,49} & \multirow[b]{2}{*}{2,02} \\
\hline $\begin{array}{l}\text { Variâncias iguais não } \\
\text { assumidas }\end{array}$ & & & $-1,961$ & 260,79 & ,050 & & \\
\hline
\end{tabular}

Fonte: Dados da pesquisa (2020).

Na comparação de duas ou mais médias, é necessário realizar a análise da variância, que compara a variabilidade entre as médias amostrais dos grupos. No Teste de Levene, sendo o $p$-value $=0,003$ (menor do que 0,05 ), infere-se que as variâncias não são homogêneas e, assim, a estatística de teste a utilizar para o Teste t é a que não assume variâncias iguais.

Quando no Teste to valor de $p \leq \alpha$ : a diferença entre as médias é estatisticamente significativa. Se o valor de $p$ for menor ou igual ao nível de significância, você deve aceitar a hipótese teórica. Portanto, neste estudo confirma-se a hipótese teórica que afirma que a divulgação dos Relatos Integrados influencia positivamente no julgamento e tomada de decisão de investidores. Existe diferença estatística entre as médias do grupo 1 de controle e o grupo 2, grupo experimental. Este resultado corrobora com o objetivo do Relato Integrado, que é melhorar as informações quanto à qualidade de sua natureza e, assim, proporcionar aos provedores de capital financeiro uma alocação mais eficiente dos recursos. Também mostra que 0 segundo objetivo do Relato Integrado, que é apresentar uma linguagem mais coesa e otimizada das informações corporativas, afeta a capacidade das organizações de gerarem valor ao longo prazo. E o terceiro objetivo, que é integrar os capitais e criar um pensamento integrado para tomada de decisão e de ações que focam na geração de valor, também é confirmado pelos resultados deste estudo (IIRC, 2013; Humphrey et al., 2017).

Foram realizadas algumas análises complementares com dados que visavam determinar quais os 
fatores que influenciaram no julgamento e tomada de decisão do investimento. Foram levantados os seguintes dados: o grupo de contas que apresentou maior influência foi a Demonstração de Resultados 3,82; na sequência, foram as informações contidas no grupo de contas do Ativo Circulante com 3,21. 0 terceiro fator que influenciou foi o grupo de contas do Patrimônio Líquido e, em quarto, foi do Balanço Patrimonial. Não houve diferença estatística entre os grupos 1 e 2 nestes dados. Cabe destacar que nessa primeira parte a análise considerou apenas as demonstrações contábeis, não levou em consideração o relato integrado. Essa ação está em linha com a busca por obtenção de mesmo parâmetro de comparação entre os grupos 1 e 2.

Ainda para o grupo 2 foi perguntado sobre a influência das informações contidas no Relato Integrado quanto aos capitais e, referente aos principais indicadores, o segundo item apresentou maior relevância, com 2,24 sobre 1,96. A análise observou apenas a percepção da influência do relato integrado para o grupo 2, grupo que recebeu o tratamento experimental com a inclusão do RI. Assim, percebe-se que os indicadores do Relato Integrado influenciaram com maior peso a decisão do investimento.

Esta seção apresentou análise descritiva referente ao julgamento e à tomada de decisão de investimento classificada pelos discentes e os valores reais a serem investidos. Os resultados das médias de investimentos e do Teste t verificaram que existe influência do Relato Integrado no julgamento e tomada de decisão para investimentos na empresa.

\subsection{Discussão dos Resultados}

A pesquisa buscou averiguar a confirmação ou refutação da hipótese teórica levantada, que propunha ser a divulgação dos Relatos Integrados uma influência positiva no julgamento e na tomada de decisão dos investidores. Pela análise descritiva dos dados, percebe-se uma predominância dos respondentes do curso de Ciências Contábeis e também uma preferência masculina na convicção de não investir na empresa ao serem consideradas todas as frequências negativas, enquanto na convicção de investir na empresa não existe diferença relevante entre os gêneros.

Ainda pela análise descritiva, as médias apresentaram diferenças entre os grupos, o que fornece evidências de que existe influência positiva entre a apresentação do RI e a disposição dos investidores em empregar recursos na organização. Isto é congruente com a literatura. Atkins e Maroun (2015) apontam que - RI é visto como uma melhoria sobre os tradicionais relatórios anuais por integrarem métricas de divulgação de sustentabilidade organizacional. Assim, essas informações contidas no RI possuem capacidade de alargar o desembolso de investimento por parte dos investidores, uma vez que na amostra analisada os participantes da pesquisa mostraram-se mais propensos a desembolsar valores maiores a partir do momento que tiveram contato com informações do RI. Esse fato, implica na forma como os acionistas irão se posicionar no mercado no que tange a possibilidade de consulta ao RI como um ponto de partida para a tomada de decisão. Dessa forma, é visto que o RI, por consequência, cria valor para as organizações (IIRC, 2013), à medida que a partir de uma narrativa fluida e inscrita na combinação dos mais diversos capitais disponíveis afeta a decisão do acionista (Alves et al., 2017).

Cheng et al. (2015) apontam o RI como um instrumento estratégico das informações que podem ser relevantes para tomada de decisão nos investimentos. Tal fato ganha ainda maior subsídio com o desenvolvimento da investigação. Assim, os processos e as informações presentes no RI apresentam-se como uma sinalização benéfica aos tomadores de decisão, o que a curto e longo prazo pode contribuir para o fomento de um campo disciplinar que preze pela relevância informacional do RI frente à tomada de decisão, de modo a incluí-lo no bojo de demonstrativos financeiros, econômicos e sociais compulsórios das organizações brasileiras, como já acontece na África do Sul.

Os estudos de Frost et al. (2007), Hong e Kacperczyk (2009), Zhou et al. (2017) e Haji et al. (2021) também abordam a pré-disposição dos investidores diante do RI quanto aos processos de tomada de decisão sobre investimento. Entretanto, estes estudos abordam a aceitação de uma menor taxa de retorno como resultado da redução do risco diante das informações apresentadas. Dessa forma, observa-se que o advento do $\mathrm{RI}$ representa uma necessidade informacional, à medida que um movimento advindo de vários usuários da informação contábil. Nesse ponto, os resultados da influência do RI nos níveis de investimentos podem ser visualizados a partir também de uma perspectiva econômica, uma vez que a geração de valor se torna evidente mediante ao comportamento praticado pelos participantes do experimento (Frost et al., 2007). Quanto a aceitabilidade das taxas de retorno menor diante dos resultados já socializados na literatura, cabe maiores investigações frente ao perfil do investidor brasileiro.

Hong e Kacperczyk (2009) discorrem que o RI pode ser entendido como um processo advindo de normas sociais. Nesse ponto, clarifica-se esse argumento também para a presente investigação, visto que a combinação dos inúmeros capitais que a empresa dispõe para gerir foram influentes na tomada de decisão dos investidores. Nessa perspectiva, as normas sociais e a gestão dos capitais contribuem para conduzir o comportamento das pessoas no mercado de capitais.

Zhou et al. (2017) apontam que o RI é uma resposta às volumosas e desarticuladas demonstrações financeiras. Nesse aspecto, os elaboradores desse relatório pregam pelo alinhamento informacional entre os aspectos qualitativos e quantitativos da informação contábil. Para esta pesquisa há alinhamento com as 
discussões de Zhou et al. (2017) visto que as informações contidas no Rl somadas aos mecanismos já existem contribuem para a tomada de decisão no mercado de capitais. Em específico, os níveis de investimentos dos participantes da pesquisa em termos de tomada de decisão são alargados quando do contato com as informações contidas no RI. Foi analisada a possibilidade de o indivíduo dizer quanto investiria em valor real caso houvesse um orçamento de $R \$ 100.000,00$ para investimentos em carteira. Os resultados apresentam uma distinção entre os grupos na média do valor investido de $R \$ 29.237,33$ para o grupo 1, enquanto o grupo 2 investiria $R \$ 35.845,22$. A mediana e a moda também forneceram evidências de que o grupo 2 está propenso a investir maior valor em empresas que apresentam o Relato Integrado.

A partir da propensão a investir do participante do experimento, implicações psicológicas são advindas desse processo, à medida que, observa-se que o participante consegue fornecer enfoques distintos para cada uma das dimensões inscritas nos demonstrativos contábeis e nas informações contidas no $\mathrm{RI}$, o que aponta para um julgamento multidimensional, quanto às categorias informacionais que 0 participante demanda para a tomada de decisão, alinhando-se às proposições de Bacaro et al. (2020).

Haji et al. (2021) sinalizam que o valor da empresa é impactado a partir de suas ações ambientais e relacionadas à sustentabilidade. Esses achados corroboram a pesquisa aqui disponibilizada e socializada com o campo disciplinar, à medida que o contato com as informações advindas do RI alteraram o nível de investimento dos participantes do experimento, o que a curto e longo prazo pode contribuir para a alteração da paisagem de tomada de decisão no mercado de capitais. Um ponto resgatado pelos autores é o fato da forma como os investidores recebem a informação relacionada ao Relato Integrado, essa forma e essa tempestividade podem alterar a sua decisão no mercado.

Considerando que o Teste t apresentou uma significância de 0,05, limite para determinar diferença estatística significativa entre os grupos analisados ao nível de $5 \%$, o experimento realizado confirmou a hipótese teórica e permitiu inferir que o Relato Integrado apresenta influência positiva sobre o julgamento e a tomada de decisão de investidores. Isto contribui com a literatura por fornecer dados empíricos que corroboram os estudos de Atkins e Maroun (2015), Cheng et al. (2015) e Haji et al. (2021).

Além do mais, apontam vestígios dos efeitos do RI em espaço brasileiro, visto a não obrigatoriedade deste relatório e incipiência do mesmo em termos de permeabilidade junto as empresas brasileiras. Como contribuição prática fornece vestígios de que o Relato Integrado apresenta valor por intermédio das informações de sustentabilidade da organização e da combinação da apresentação da gestão dos inúmeros capitais disponíveis à organização. Tal cenário pode ser um instrumento consultivo para os elaboradores desse instrumento de comunicação com os stakeholders.

\section{Conclusão}

Este estudo é motivado pela necessidade de fornecer informações a respeito dos efeitos das informações contidas no RI sobre os investimentos e tomada de decisão de investidores. Tal direcionamento é pautado pela crescente importância que este relatório tem alcançado no escopo corporativo a nível mundial. Dessa forma, esta pesquisa teve como objetivo verificar se a divulgação do Relato Integrado influencia positivamente no julgamento e na tomada de decisão dos investidores, visto que este relatório não é compulsório em grande parte do mundo, com exceção da África do Sul.

Os resultados evidenciam que há uma melhoria no nível de investimento e na propensão para o investimento dos participantes que tiveram contato com as informações contidas no Rl. Esses resultados são obtidos a partir de um experimento com alunos dos cursos de Administração, Ciências Contábeis e Ciências Econômicas de uma instituição pública. Assim, em resposta àhipótese de pesquisa denota-se que a divulgação dos Relatos Integrados influencia positivamente no julgamento e tomada de decisão de investidores. Nesse ínterim, a pesquisa contribui com vestígios da utilização do RI na gestão das organizações para fins não mandatários, mas com fins administrativos e com cunho de buscar investidores tanto no mercado de capitais como investidores internos para organizações.

\subsection{Implicações dos Achados}

O trabalho visa a contribuir com os estudos na temática de Relato Integrado, assim como nos estudos de julgamento e tomada de decisão. Dessa forma, estima-se que se disponibiliza para o campo disciplinar um material consultivo que combina informações já compulsórias advindas do mercado de capitais e informações que estão em um período de fomento no que concerne à popularidade entre as empresas, o qual fornece argumentos para as organizações no que paira utilizar o RI como um instrumento de comunicação com os usuários externos e ao mesmo tempo como uma ação para a captação de novos acionistas e oportunidade de vantagem competitiva.

A investigação preenche um gap na literatura nacional a respeito da relação entre $\mathrm{Rl}$ e tomada de decisão, visto que a incipiência da temática no Brasil, demanda por esforços de pesquisadores e profissionais para a criação de um ambiente que o RI seja visualizado como um instrumento sólido que garante a vantagem competitiva e perfaça com que as organizações cumprem o seu papel de prestar contas à sociedade e aos interessados nas informações plurais advindas do ambiente empresarial. 
A pesquisa, da mesma forma, como é pregado por Zhou et al. (2017) lança olhares sobre as consequências da prática do RI no mercado de capitais. Tal fato abre espaço para discussões voltadas para os aspectos regulatório e até mesmo frente a periodicidade desse instrumento de comunicação com os stakeholders. Por fim, a pesquisa apresenta como implicação a necessidade de não negligência das ações empresariais envolvendo os capitais financeiros, manufaturados, intelectuais, humanos, sociais e de relacionamentos e naturais, o que, a curto e longo prazo pode alterar as fontes informacionais para a tomada de decisão no mercado de capitais.

\subsection{Limitações e Pesquisas Futuras}

Apresentou-se como limitação do estudo o fato de a amostra ser composta por indivíduos pertencentes à mesma instituição de ensino. Dessa forma, sujeitou a amostra a um viés de seleção, o que pode fornecer efeitos explícitos ou potenciais sobre os resultados da pesquisa. Como limitação metodológica, aponta-se o fator temporal, uma vez que o estudo fora desenvolvido no final do período letivo. Para futuros estudos, sugere-se realizar um experimento com profissionais atuantes no mercado de ações, visto que eles podem vir a apresentar novos dados sobre a influência no julgamento e tomada de decisão do investidor referente à utilização do Relato Integrado, o que pode somar-se aos resultados disponibilizados nesta investigação. Acredita-se ser relevante também investigar os efeitos do RI na redução do custo de capital próprio nas empresas e por consequência os reflexos na tomada de decisão dos investidores. As propostas de investigações envolvendo RI são plurais visto a necessidade do campo para a criação de um espaço disciplinar sobre a temática. Por fim, avançar na temática, demanda inclusão de elementos voltados para a evidenciação de informação, com vistas a alinhar esses processos as questões psicológicas elencadas nesta pesquisa.

\section{Referências}

Adams, C. A. (2017). The Sustainable Development Goals, integrated thinking and the integrated report. Recuperado em 19 junho, 2021, de https://researchbank.swinburne.edu.au/file/473d5e90-5a04-4ad4-8a7ee70bab78f62f/1/2017-adams-sustainable development goals.pdf.

Aguiar, A. B. (2017). Pesquisa experimental em contabilidade: propósito, desenho e execução. Advances in Scientific and Applied Accounting, 10(2), 224-244. DOI: http://dx.doi.org/10.14392/asaa.2017100206.

Alves, N. J. F., Kassai, J. R., Lucas, E. C., \& Ferreira, H. M. G. (2017). Relato Integrado e o formato da informação financeira para evidenciar a criação de valor das empresas do Programa Piloto. Revista Evidenciação Contábil \& Finanças, 5(3), 99-122.

Atkins, J., \& Maroun, W. (2015). Integrated reporting in South Africa in 2012: Perspectives from South African institutional investors. Meditari Accountancy Research. 23(2), 197-221. DOI: https://doi.org/10.1108/MEDAR-07-2014-0047.

Bonner, S. E. (2007). Judgment and decision making in accounting. Upper Saddle River, N.J.: Nova Jersey, EUA: Prentice Hall.

Bortoli, D., Costa, N. \& Goulart, M. (2016). Teoria do prospecto, traços da personalidade, teste de reflexão cognitiva e avaliação do perfil do investidor: um estudo em finanças comportamentais. Anais do XIX Encontro de Economia da Região Sul, Florianópolis, SC.

Briem, C. R., \& Wald, A. (2018). Implementing third-party assurance in integrated reporting: Companies' motivation and auditors' role. Accounting, Auditing \& Accountability Journal. 31(5), 1461-1485. DOI: https://doi.org/10.1108/AAAJ-03-2016-2447.

Bucaro, A. C., Jackson, K. E., \& Lill, J. B. (2020). The influence of corporate social responsibility measures on investors' judgments when integrated in a financial report versus presented in a separate report. Contemporary Accounting Research, 37(2), 665-695. DOI: https://doi.org/10.1111/1911-3846.12542

Cheng, M. M., Green, W. J., \& Ko, J. C. W. (2014). The impact of strategic relevance and assurance of sustainability indicators on investors' decisions. Auditing: A Journal of Practice \& Theory, 34(1), 131-162. DOI: https://doi.org/10.2308/ajpt-50738.

Cohen, J. R., Holder-Webb, L. L., Nath, L., \& Wood, D. (2012). Corporate reporting of nonfinancial leading indicators of economic performance and sustainability. Accounting Horizons, 26(1), 65-90. DOI: https://doi.org/10.2308/acch-50073. 
Corrar, L., Paulo, E., Dias Filho, J. M. \& Rodrigues, A. (2011). Análise multivariada para os cursos de administração, ciências contábeis e economia. São Paulo: Atlas.

Dey, C., \& Burns, J. (2010). Integrated reporting at Novo Nordisk. In Dey, C., \& Burns, J. Accounting for Sustainability (pp. 233-250). Londres, Reino Unido: Routledge.

Du Toit, E. (2017). The readability of integrated reports. Meditari Accountancy Research. 25(4), 629-653. DOI: https://doi.org/10.1108/MEDAR-07-2017-0165.

Eccles, R. G., Serafeim, G., \& Krzus, M. P. (2011). Market interest in nonfinancial information. Journal of Applied Corporate Finance, 23(4), 113-127. DOI: https://doi.org/10.1111/i.1745-6622.2011.00357.x.

Formation of the International Integrated Reporting Committee (IIRC) (2015). The International IR Framework. Recuperado em 17 fevereiro, 2020, de http://integratedreporting.org/wpcontent/uploads/2015/03/13-12-08-THE-INTERNATIONAL-IR-FRAMEWORK-Portugese-final-1.pdf

Frost, G., Jones, S., Loftus, J., \& Van Der Laan, S. (2007). An empirical examination of the market returns and financial performance of entities engaged in sustainability reporting. Australian Accounting Review, 17(41), 78-87. DOI: https://doi.org/10.1111/i.1835-2561.2007.tb00456.x.

Garcia, A, Ciasca, D \& Marçal, A. (2019). Como o Relato Integrado vem sendo disseminado no contexto das Organizações Privadas e Públicas? Anais XIX USP International Conference In Accounting, São Paulo, SP.

Gomes, F. B. (2007). Processo de tomada de decisão do investidor individual brasileiro no mercado acionário nacional: um estudo exploratório enfocando o efeito disposição e os vieses da ancoragem e do excesso de confiança. (Dissertação DE Mestrado). Universidade Presbiteriana Mackenzie, São Paulo, Brasil.

Hair Jr, J. F., Black, W.C., Babin, B.J., Anderson, R.E. \& Tatham, R.L. (2009). Análise multivariada de dados. Porto Alegre: Bookman.

Haji, A. A., \& Anifowose, M. (2016). The trend of integrated reporting practice in South Africa: ceremonial or substantive?. Sustainability Accounting, Management and Policy Journal. 7(2), 190-224. DOI: https://doi.org/10.1108/SAMPJ-11-2015-0106.

Haji, A. A., \& Anifowose, M. (2017). Initial trends in corporate disclosures following the introduction of integrated reporting practice in South Africa. Journal of Intellectual Capital. 18(2), 373-399. DOI: https://doi.org/10.1108/JIC-01-2016-0020.

Haji, A. A., Coram, P., \& Troshani, I. (2021). Effects of integrating CSR information in financial reports on investors' firm value estimates. Accounting \& Finance, 61(2), 3605-3647.DOI: https://doi.org/10.1111/acfi.12713.

Hastie, R. (2001). Problems for judgment and decision making. Annual review of psychology, 52(1), 653683. DOI: https://doi.org/10.1146/annurev.psych.52.1.653.

Hong, H., \& Kacperczyk, M. (2009). The price of sin: The effects of social norms on markets. Journal of financial economics, 93(1), 15-36. DOI: https://doi.org/10.1016/i.jineco.2008.09.001.

Humphrey, C., O'Dwyer, B., \& Unerman, J. (2017). Re-theorizing the configuration of organizational fields: the IIRC and the pursuit of 'Enlightened' corporate reporting. Accounting and Business Research, 47(1), 3063. DOI: https://doi.org/10.1080/00014788.2016.1198683.

IIRC-Formation of the International Integrated Reporting Committee. (2013). The International IR Framework. Recuperado em 08 julho, 2021, de https://www.aeca.es/old/temporales2013/the international ir framework.pdf

Institute of Directors in Southern Africa (IODSA). (2009) King Committee on Corporate Governance, \& Institute of Directors (South Africa). Recuperado em 07 julho, 2021, de https://cdn.ymaws.com/www.iodsa.co.za/resource/resmgr/king iii/King Report on Governance fo.pdf.

Joos, P. (2019). How can research address the trends in corporate reporting. Anpcont (Oral comunication). 
2019.

Libby, R., Bloomfield, R., \& Nelson, M. W. (2002). Experimental research in financial accounting. Accounting, organizations and society, 27(8), 775-810. DOI: https://doi.org/10.1016/S0361-3682(01)00011-3.

Mervelskemper, L., \& Streit, D. (2017). Enhancing market valuation of ESG performance: Is integrated reporting keeping its promise?. Business Strategy and the Environment, 26(4), 536-549. DOI: https://doi.org/10.1002/bse.1935.

Pestana, M. H. \& Gageiro, J. G. (2003) Análise de dados para ciências sociais: a complementaridade do SPSS. 3.ed. Lisboa: Edições Silabo.

Santana, D., Dias, D., Espejo, M. \& Silveira, N. (2019). Relato Integrado: agenda de pesquisa a partir do estado da arte. Anais do XVI Congresso USP de iniciação Científica em Contabilidade. São Paulo, SP.

Santos, C. A. D., \& Cunha, P. R. D. (2021). Effect of Trust between the Time Pressure and Complexity in Judging and Decision-Making in Auditing. Revista de Administração Contemporânea, 25(5), e-200037. https://doi.org/10.1590/1982-7849rac2021200037.en

Smith, M. (2003). Research methods in accounting. London: Sage.

Soares, R. A., Abreu, M. C. S. D., Rebouças, S. M. D. P., \& Marino, P. D. B. L. P. (2020). Efeito do sistema nacional de negócios sobre a evidenciação social e ambiental: uma comparação entre Brasil e Canadá. Revista Brasileira de Gestão de Negócios, 22(01), 29-47. DOI: https://doi.org/10.7819/rbgn.v22i1.4042

Sprinkle, G. B. (2003). Perspectives on experimental research in managerial accounting. Accounting, Organizations and Society, 28(2-3), 287-318. DOI: https://doi.org/10.1016/S0361-3682(01)00058-7.

Zhou, S., Simnett, R., \& Green, W. (2017). Does integrated reporting matter to the capital market?. Abacus, 53(1), 94-132. DOI: https://doi.org/10.1111/abac.12104.

* Uma versão preprint do artigo foi apresentada no XLIV ENCONTRO DA ANPAD, ENANPAD 2020.

\section{NOTAS}

\section{AGRADECIMENTOS}

Agradecemos a Pró-Reitoria de Pesquisa e Pós-Graduação (PRPPG) da Universidade Estadual do Oeste do Paraná (UNIOESTE). Agradecemos a Coordenação de Aperfeiçoamento de Pessoal de Nível Superior - CAPES, por meio de bolsa de estudo ao PPGC da Unioeste - para Simone Boruck Klein, no período de 2019. Agradecemos a Fundação Universidade Federal de Mato Grosso do Sul (UFMS/MEC - Brasil).

\section{CONTRIBUIÇÃO DE AUTORIA}

Concepção e elaboração do manuscrito: Colla, P. E. B. ., Klein, S. B. ., Dal Vesco, D. G. ., \& Santos, C. A. dos.

Coleta de dados: Colla, P. E. B. ., Klein, S. B.

Análise de dados: Colla, P. E. B. ., Klein, S. B. ., Dal Vesco, D. G. ., \& Santos, C. A. dos.

Discussão dos resultados: Colla, P. E. B. ., Klein, S. B. ., Dal Vesco, D. G. ., \& Santos, C. A. dos.

Revisão e aprovação: Colla, P. E. B. ., Klein, S. B. ., Dal Vesco, D. G. ., \& Santos, C. A. dos.

\section{CONJUNTO DE DADOS DE PESQUISA}

O conjunto de dados que dá suporte aos resultados deste estudo não está disponível publicamente.

\section{FINANCIAMENTO}

O presente trabalho foi realizado com apoio da Pró-Reitoria de Pesquisa e Pós-Graduação (PRPPG) da Universidade Estadual do Oeste do Paraná (UNIOESTE). A autora Simone Boruck Klein contou com bolsa da CAPES durante o ano de 2019, em conformidade com a Portaria $n^{\circ} 206$, de 4 de setembro de 2018, "o presente trabalho foi realizado com apoio da Coordenação de Aperfeiçoamento de Pessoal de Nível Superior - Brasil (CAPES) - Código de Financiamento 001".

\section{CONSENTIMENTO DE USO DE IMAGEM}

Não se aplica. 


\section{APROVAÇÃO DE COMITÊ DE ÉTICA EM PESQUISA}

Não se aplica.

\section{CONFLITO DE INTERESSES}

Não se aplica.

\section{LICENÇA DE USO}

Os Direitos Autorais para artigos publicados neste periódico são do autor, com direitos de primeira publicação para a Revista. Em virtude de aparecerem nesta Revista de acesso público, os artigos são de uso gratuito, com atribuições próprias, em aplicações educacionais, de exercício profissional e para gestão pública. A Revista adotou a licença Creative Commons Atribuição 4.0 Internacional - CC BY NC ND. Esta licença permite acessar, baixar (download), copiar, imprimir, compartilhar, reutilizar e distribuir os artigos desde que com a citação da fonte, atribuindo os devidos créditos de autoria. Nesses casos, nenhuma permissão é necessária por parte dos autores ou dos editores. Autores têm autorização para assumir contratos adicionais separadamente, para distribuição não-exclusiva da versão do trabalho publicada nesta revista (ex.: publicar em repositório institucional ou um capítulo de livro).

\section{PUBLISHER}

Universidade Federal de Santa Catarina. Curso de Ciências Contábeis e Programa de Pós-graduação em Contabilidade. Publicação no Portal de Periódicos UFSC. As ideias expressadas neste artigo são de responsabilidade de seus autores, não representando, necessariamente, a opinião dos editores ou da universidade.

\section{EDITORES}

Carlos Eduardo Facin Lavarda e Suliani Rover

\section{HISTÓRICO}

Recebido em: 20/10/2020 - Revisado por pares em: 17/05/2021 - Reformulado em: 20/07/2021 Recomendado para publicação em: 21/07/2021 - Publicado em: 04/12/2021 